\title{
Diagnostics of Uneven Heating of the Adsorbent by Microwave Radiation and Measures to Increase the Uniformity of Its Heating
}

\author{
Sergey Dobrotvorskiy ${ }^{1}$, Ludmila Dobrovolska ${ }^{1}$, Yevheniia Basova ${ }^{1}$, Borys Aleksenko ${ }^{1 *}$ \\ 1 Department of Mechanical Engineering Technology and Metal-Cutting Machines, Institute of Education and Science in \\ Mechanical Engineering and Transport, National Technical University "Kharkiv Polytechnic Institute", 2, Kyrpychova str., \\ 61002 Kharkiv, Ukraine \\ * Corresponding author, e-mail: e.v.basova.khpi@gmail.com
}

Received: 30 September 2018, Accepted: 27 February 2019, Published online: 09 April 2019

\begin{abstract}
In Europe, $3 \%$ of the electricity consumed by industry is spent on the production of compressed air. At the same time, the payment for electricity consumed by the compressor is the largest share in the structure of the factorys costs. In modern production, compressed air requires drying to meet the requirements of the equipment and for various technological processes. In this case, a large amount of compressed air is lost thus, improving the design of air dryers is an important step for improving energy efficiency. In this paper is developing a method for reducing the energy costs of the heated desiccant dryers is developed by mean of regenerating adsorbents using microwave energy.

In the process of developing heaters using microwave energy, the main problem is the achievement of a uniform heating of the material. The same problem also arises when using microwave energy to regenerate the adsorbent in the adsorption dryer. Due of above-mentioned, the problem by dynamically changing the configuration of the heater chamber and waveguide systems is solved by using of increasing the uniformity of heating and two opposite waveguides in the heater design with a variable phase of one of them. A specific condition for conducting experiments is obtained. Particularly the adsorption dryer chamber is a cylindrical vessel that is filled with an adsorbent and has predetermined proportions. A significant change of these proportions adversely affect at the adsorption process during the operation of the desiccant.
\end{abstract}

Keywords

heating dryers, microwave energy, radiation, phase, adsorbent regeneration, silica gel, desorption

\section{Introduction}

Modern adsorption dryers during the process of regenerating the adsorbent uses hot air, which is heated by external heaters and transported to the cavity of the adsorption column [1]. Heating the moisture directly in adsorbent pores is a useful step towards improving the energy saving of the regenerative drying of the adsorbent. This is possible if microwave energy is used to heat the adsorbed moisture in the desorption process.

Drying with the use of microwave heating is characterized by ecological purity [2], absence of thermal inertia and high coefficient of efficiency [3-5]. Heating by using the microwave energy has some positive side effects. Thus, the effect of reducing the surface tension coefficient of water [6-9] accelerates evaporation [10].
Also, increasing vapor pressure in pores of the adsorbent promotes the acceleration of the desorption process [11].

The main problem of increasing the efficiency of the microwave heater is to enhance the uniformity of the distribution of microwave energy inside the heating chamber to increase the efficiency and stabilize the heating of the materials [12]. In practice, as a rule, this is achieved by changing the mutual location of the source of microwave energy and the material being heated [13]. There is still a way to increase the uniformity of heating due to the fact that a traveling wave effect is created in the heater chamber $[14,15]$. This method is the best way to improve the uniformity of heating of inhomogeneous materials, simplify the mechanical design of the heater and to increase 
the automation of the process [16]. Also, the change in the configuration of the electromagnetic field in the heater chamber can be applied in combination with the displacement of the being heated object [17].

The practice of using microwave energy shows that the intension of the electromagnetic field is not evenly distributed in the volume of the adsorbent. This leads to damage of the adsorbent due to its local overheating and does not allow for intensive drying by increasing the radiation power. Researchers who are faced with this problem directly point that the main difficulty remains in the microwave waveguide and applicator design which requires further investigations on dielectric characterization of adsorbent systems [18].

The purpose of this research work is to investigate the possibility of achieving uniform heating of silica gel without moving the heated material inside the cavity of the adsorption column. A positive result of the research will allow using the traveling wave effect in the design of adsorption dryers to achieve uniform heating of the adsorbent during the regeneration process.

In this article, a computer simulation [19-24] of the process of silica gel heating in the cavity of the adsorption column is considered with the creation of the traveling wave effect.

\subsection{Materials and Methods}

The heater design should provide intensive heating using the energy of electromagnetic radiation due to redistribution of electromagnetic radiation in the chamber in the entire volume of the dried material without its local overheating and with less hardware costs.

Microwave energy reaches different coordinates of space in various ways. The electric field strength in a given volume region is the vector sum of the fields, which are formed by waves of all directions. As a result of superposition, in addition to the numerical value of the field, one must also take into account the spatial orientation of the field. Thus, the total field can turn out to be less than each of terms. Waves that come to this coordinate space, differ in phases. Therefore, due to interference, in the various coordinates of space the sum of the same waves will give a different result in the range from 0 to the arithmetic sum of the amplitudes. The intensity map of the electromagnetic field can be obtained by computer simulation of the process of heating the humid adsorbent using microwave energy.

The presented computer model uses the software on the base of the finite element method, which allows to statically and dynamically examine the pattern of electromagnetic field intensity distribution and silica gel temperature, visualize and evaluate the achieves. The model corresponds to the configuration of the desiccant adsorption column with a capacity of $0.5 \mathrm{~m}^{3} / \mathrm{min}$ (Fig. 1 (a)) and represents the cross section of the column at the level of two opposing microwave energy sources (Fig. 1 (b)).

2-D model is used for better visibility of the results and allows accelerating calculations. The Fig. 1 clearly shows the changes of the electromagnetic field strength in a range of phase $\pi \ldots 2 \pi \mathrm{rad}$.

In this paper the control of microwave power distribution is performed by changing the phase of one of the microwave energy sources. This is a way to cause a change in the overall structure of the electric field.

Areas with the maximum and minimum amplitude of electromagnetic oscillations are displaced in space and change places.

As a result, each section of the adsorption column volume is alternately subjected to the influence of fields of different configuration and intensity. The effect of microwave energy can be fairly uniform with a large number of combinations of the electromagnetic field intensity.

To solve this problem, computer simulation is carried out by using COMSOL Multiphysics software on the basis of the finite element method, which allows modelling the propagation of the electromagnetic field intensity in space.

The alternative calculation methods of a mathematical model using Mathlab are based on the Fourier differential thermal conductivity equation and use a cylindrical

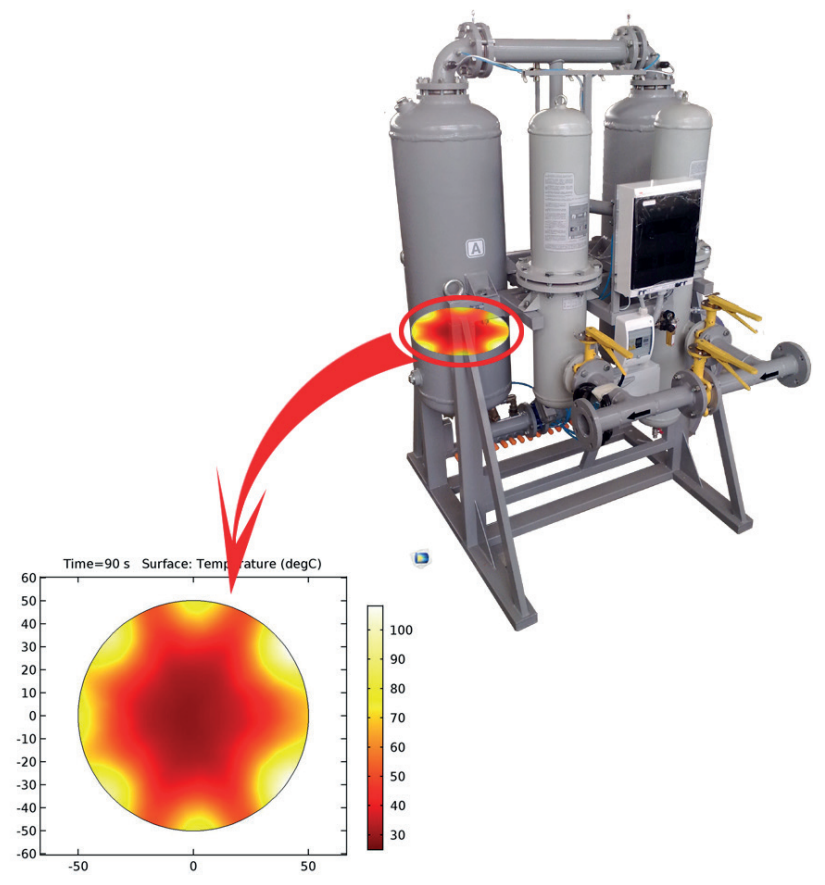

Fig. 1 The adsorption dryer's column (a) and its cross section (b) 
coordinate system. When solving the model using this software environment, in the process of setting the initial conditions in the form of functional dependence of temperature on the coordinate, there is a need for functional expression of the temperature distribution in the calculated volume. Also, the magnitude of the energy impact, which depends on the intensity of the electromagnetic field at a given point in the volume of the cylinder, must be represented as a functional dependence. Data on the intensity of the electromagnetic field in the volume of the adsorbent may be also obtained using the software Ansoft and Komsol, the model in which is built using the Cartesian coordinate system, and the resulting solution is stored in a matrix form. In order to accelerate the calculations and eliminate the error that arises when expressing the solution obtained as a functional dependence on the radius and cylinder length, it was decided to perform calculations using the Komsol multi-physical software product directly in the Cartesian coordinate system. Previously obtained data on the intensity of the electromagnetic field are used as the initial conditions for calculating the temperature and its distribution in the cylinder at the subsequent stage of the calculation in the same Cartesian coordinate system. This calculation in a single integrated multi-physical environment is more convenient, faster and more accurate.

The pattern of the travelling wave field inside the waveguide can be determined by solving the Maxwell equation [25]. Equation (1), which is solved by a two-dimensional solving device, was obtained directly from the Maxwell equation [26].

$\nabla \times\left(\frac{1}{\mu_{\gamma}} \nabla \times E(x, y)\right)-k_{0}^{2} \varepsilon_{\gamma} E(x, y)=0$,

where: $\mu_{\gamma}(x, y)$ - complex relative permeability; $E(x, y)$ complex amplitude representing an oscillating electric field; $\varepsilon_{\gamma}(x, y)$ - complex relative dielectric permeability; $k_{0}$ - phase constant of free space, which is equal to

$k_{0}=\omega \sqrt{\mu_{0} \cdot \varepsilon_{0}}$,

where: $\omega$ - angular frequency $(\omega=2 \pi f)$, where $f$ - frequency $[\mathrm{Hz}] ; \mu_{0}-$ magnetic permeability of the medium; $\varepsilon_{0}$ - dielectric permittivity of the medium.

In the process of solving Eq. (2), a two-dimensional solving procedure allows obtaining a picture of the field for the complex complex amplitude $E(x, y)$. This solution is independent of $z$ and $t$; and after multiplying by $\boldsymbol{e}^{-\gamma z}$ (where $\boldsymbol{\gamma}=\boldsymbol{\alpha}+\boldsymbol{j} \boldsymbol{\beta}$ is the complex propagation constant, where $\boldsymbol{\alpha}$ is the damping coefficient of the wave; $\boldsymbol{\beta}$ is the propagation constant associated with the wave, which determines the dependence of the phase angle from $z$ on time $t$ ), they will become travelling waves.

Since the calculated field pattern is valid only for one frequency, different field patterns are computed for each frequency point. For a waveguide or transmission line with a given cross-section, various base field patterns (modes) that satisfy Maxwell equations at a particular frequency. Any linear combination of these modes can exist in a waveguide. If these higher-order modes are reflected back to the excitation port or transferred to another port without much loss, then $S$-parameters associated with these modes can be calculated.

When calculating the general solution for the 3D field, the following wave equation is solved:

$\nabla \times\left(\frac{1}{\mu_{\gamma}} \nabla \times E(x, y, z)\right)-k_{0}^{2} \varepsilon_{\gamma} E(x, y, z)=0$,

where: $\mu_{\gamma}$-complex relative permeability; $E(x, y, z)$ - a complex vector representing the electric field; $\varepsilon_{\gamma}$-complex relative permittivity; $k_{0}$ - phase constant of free space.

Equation (3) is analogous to the Eq. (2) used in the computation of the two-dimensional field pattern in each of the ports by a two-dimensional solver. The difference is that the $3 \mathrm{D}$ solver does not accept that the electric field is a travelling wave propagating in a single direction. It is assumed that the vector $E$ is a function of $x, y$, and $z$. A real electric field is a real part of the complex amplitude, multiplied by $e^{j \omega t}$.

$$
E(r, t)=\mathrm{R}\left\{E(r) e^{j \omega t}\right\},
$$

where: $e^{j \omega t}=\cos (\omega t)+j \sin (\omega t)-$ Euler's formula; $t-$ time; $j$ - imaginary unit.

Thus, the formula for calculating the field pattern becomes [27]:

$$
E(x, y, z, t)=\mathrm{R}\left\{E(x, y, z) e^{j \omega t}\right\} .
$$

With the determined excitation at the rectangular port, the following equation is solved for the electric field vector $\boldsymbol{E}$ inside the waveguide and adsorption column cavity:

$$
\nabla \times\left(\mu_{\gamma}^{-1} \nabla \times \boldsymbol{E}\right)-\boldsymbol{k}_{0}^{2}\left(\boldsymbol{\varepsilon}_{\gamma}-\frac{\boldsymbol{j} \sigma}{\omega \varepsilon_{0}}\right) \boldsymbol{E}=0 .
$$

Having the value of the electromagnetic field strength it is possible to model the heating of the material to be dried:

$$
\boldsymbol{P}=\boldsymbol{E}^{2} \omega \varepsilon_{\gamma} \varepsilon_{0} \operatorname{tg} \sigma
$$

Simulation the propagation of thermal energy in the volume of the adsorbent and visualization of the results are 
obtained due to Eq. (7) of the dependence of the microwave radiation power on the intensity of the electromagnetic field.

\section{Model Definition}

The 2-D model (Fig. 2) is a horizontal section of the adsorption tower. The linear dimensions of the model, which are chosen for the desiccant adsorption column with a capacity of the order of $1 \mathrm{~m}^{3} / \mathrm{min}$, are given in Table 1 . The adsorption column is a metallic cylinder, connected to a $2.45 \mathrm{GHz}$ microwave source via rectangular waveguides, operating in the $\mathrm{TE}_{10}$ mode.

Inside the column there is a radio-transparent case. There is an air gap between the radio-transparent casing and the column wall. The volume of silica gel, which undergoes heating in the process of regeneration, is inside the radio-transparent case.

The model uses copper for the walls of the column and the waveguides. The walls were assumed to be perfect electric conductors and hence the tangential component of the electric field was eliminated to zero.

The sources of electromagnetic radiation are two ports with a fixed power of $500 \mathrm{~W}$, located oppositely in the calculated plane.

The study includes two parts:

1. In the first part of the study, the phase of the first port $P_{1}$ does not change, $\theta_{P 1}=0 \mathrm{rad}$. The second port $P_{2}$ phase does not change either.

2. In the second part of the study, the phase of the first port $P_{1}$ does not change. The phase of the second port $P_{2}$ changes in time according to the Eq. (8):

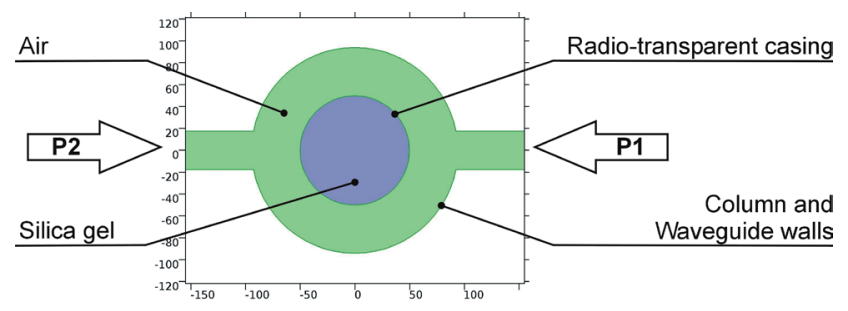

Fig. 2 2D model adsorption column cavity

Table 1 Parameters of the computer model

\begin{tabular}{lcc}
\hline Property & Dimension & Value \\
\hline Waveguide height & $\mathrm{mm}$ & - \\
Waveguide width & $\mathrm{mm}$ & 35 \\
Waveguide length & $\mathrm{mm}$ & 194 \\
The radius of the adsorption column & $\mathrm{mm}$ & 94 \\
Radius of the radio-transparent case & $\mathrm{mm}$ & 50 \\
Initial temperature & ${ }^{\circ} \mathrm{C}$ & 25 \\
\hline
\end{tabular}

$\theta_{P 2}=\boldsymbol{a b s}(w v 1(\boldsymbol{t})+1.1 \pi)$,

where: $w v 1(t)$ is smoothing waveform time-dependent function with angular frequency $=0.09 \mathrm{~Hz}$, phase $=0 \mathrm{rad}$ and amplitude $=0.78$ (Fig. 3).

The materials, used from the COMSOL Multiphysics library, are air and copper. The silica gel is determined manually (Table 2). Silica gel properties [28, 29] are corrected, by taking into account the bulk density and humidity of the wet silica gel.

The study was carried out in the time range $0 \ldots 90 \mathrm{~s}$, with the step $1 \mathrm{~s}$, at a frequency of $2.45 \mathrm{GHz}$. Measurements of the temperature and strength of the electromagnetic field were made at several control points (Fig 4). Since the model in equation is symmetrical along the $X$ and $Y$ axes, the measurement data, obtained at the control points, can be extrapolated to the whole plane of the section of the model tabbing into consideration.

\section{Results and Discussion}

\subsection{The Estimation of Tensity of the Electromagnetic} Field under the Condition $\theta_{P 1}=0 \mathrm{rad}$ and $\theta_{P 2}=0 \mathrm{rad}$ During the investigation, a static picture of the electromagnetic field strength in the simulated plane section of the adsorption column was obtained (Fig. 5).

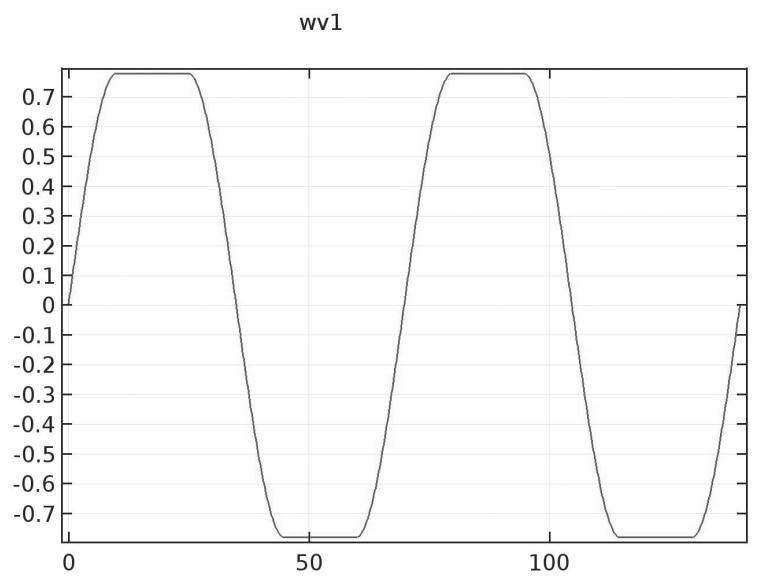

Fig. 3 Waveform time-dependent function

Table 2 Properties of Silica gel material

\begin{tabular}{lcc}
\hline Property & Dimension & Value \\
\hline Density & $\mathrm{kg} / \mathrm{m}^{3}$ & 2100 \\
Heat capacity & $\mathrm{j} /(\mathrm{kg} \cdot \mathrm{K})$ & 730 \\
Dielectric loss tan $\delta$ & 1 & $0.25 \cdot 10^{-3}$ \\
Relative permittivity & 1 & 4.2 \\
Electrical conductivity & $\mathrm{S} / \mathrm{m}$ & 0 \\
Thermal conductivity & $\mathrm{W} /(\mathrm{m} \cdot \mathrm{K})$ & 0.3 \\
\hline
\end{tabular}




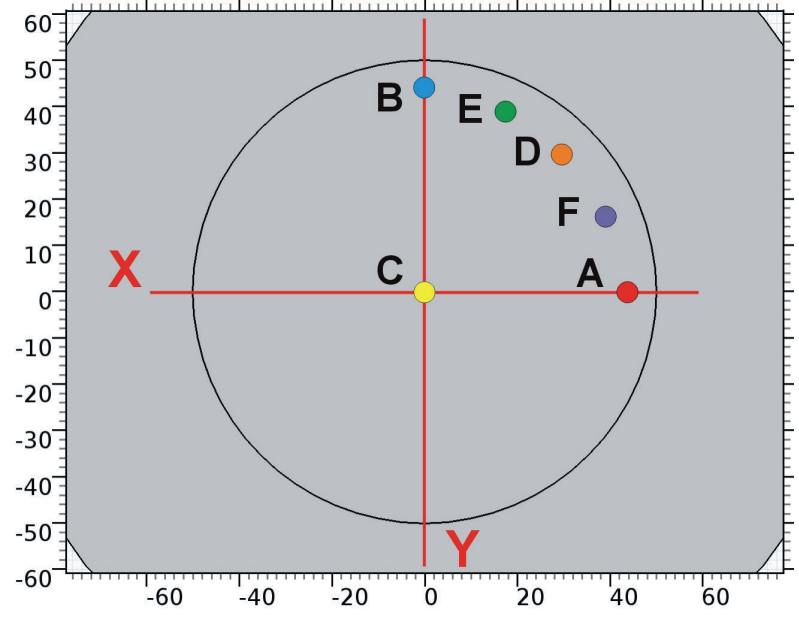

Fig. 4 The control points of the parameter measurement

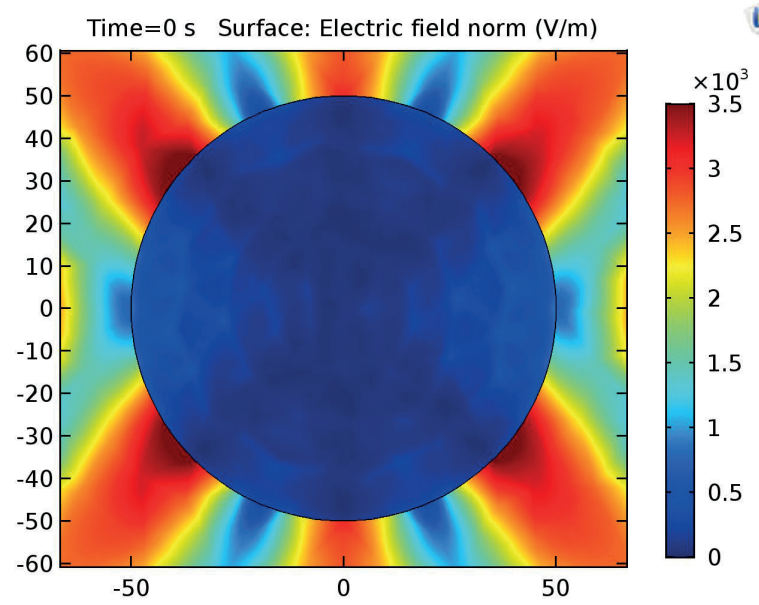

Fig. 5 The picture of the intensity of the electromagnetic field

In the areas of the material being heated, which is located in the immediate proximity of the ports (control measuring points A (Figs. 4, 6)) a higher level of electromagnetic field strength is noted, compared to the level of electromagnetic field tensity in the areas of the material being heated, that are remote from the ports (control measuring points $\mathrm{B}, \mathrm{D}$, F, E (Figs. 4, 6)). In the central regions of the material being heated (control measuring point $\mathrm{C}$ (Fig. 4)) the high tensity of the electromagnetic field is not observed (Fig. 6).

\subsection{The Change in the Temperature of Silica Gel under the Condition $\boldsymbol{\theta}_{\boldsymbol{P} 1}=0 \mathrm{rad}$ and $\boldsymbol{\theta}_{\boldsymbol{P} 2}=0 \mathrm{rad}$}

In this paper, a dynamic picture of increasing the temperature growth in the adsorbent layer was obtained (Fig. 7, Fig. 13 A).

In the regions of the material being heated, located in the immediate proximity of the ports (measuring points $\mathrm{A}$ (Fig. 4)), there is a more intense temperature increase, compared with the temperature increase in the central

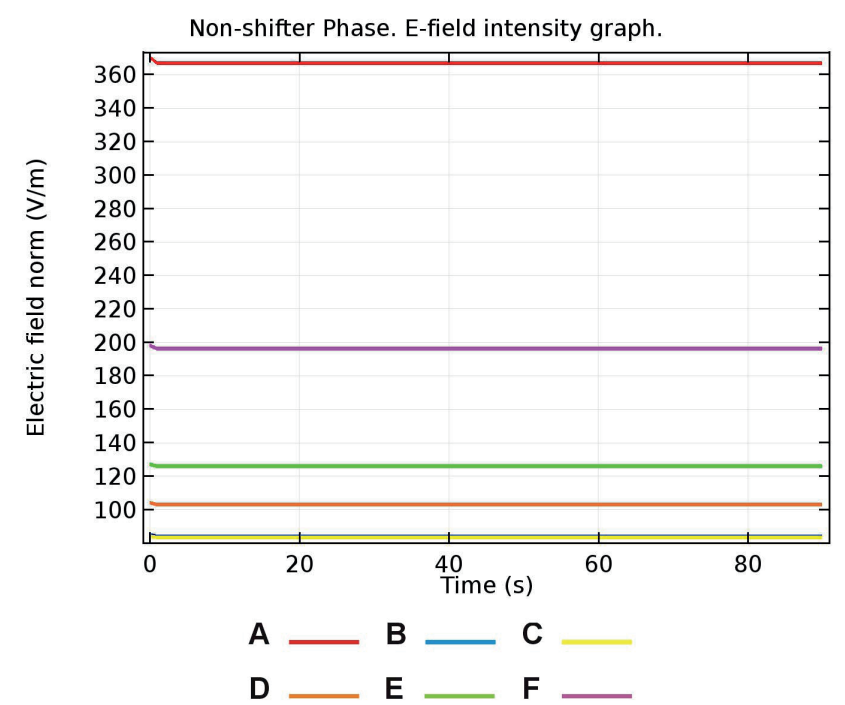

Fig. 6 The level of tensity of the electromagnetic field

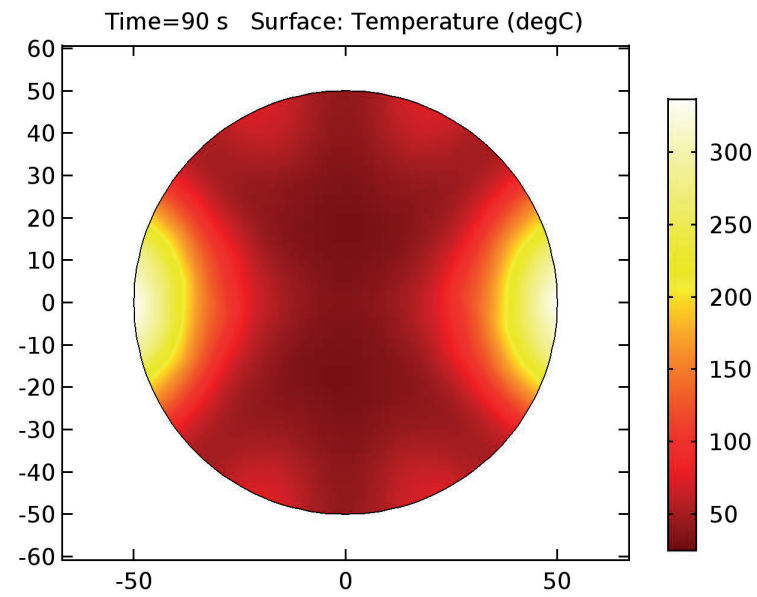

Fig. 7 Temperature rising in the adsorbent layer

regions of the material being heated and in the areas, that they are remote from ports (measuring points B, D, F, E and C (Figs. 4, 8)).

The difference between the temperature in different areas of the material, marked on the graph with red area, indicates a noticeably unevenness heating of the material.

\subsection{The Change in the Intensity of the Electromagnetic} Field under the Condition $\theta_{P 1}=0$ rad and $\theta_{P 2}=\boldsymbol{a b s}(w v 1(\boldsymbol{t})+1.1 \pi) \operatorname{rad}$

The dynamics of the phase $\boldsymbol{\theta}_{\boldsymbol{P} 2}$ change in time $\boldsymbol{t}$ is shown in the graph (Fig. 9). During the investigation, a dynamic picture of the electromagnetic field strength in the simulated of the adsorption column section plane was obtained (Fig. 10).

In the areas of the material being heated, located in the proximity of the ports (measuring points A, (Fig. 4)), and in the areas of the material, that are remote from the 
Non-shifter Phase. Temperature graph.

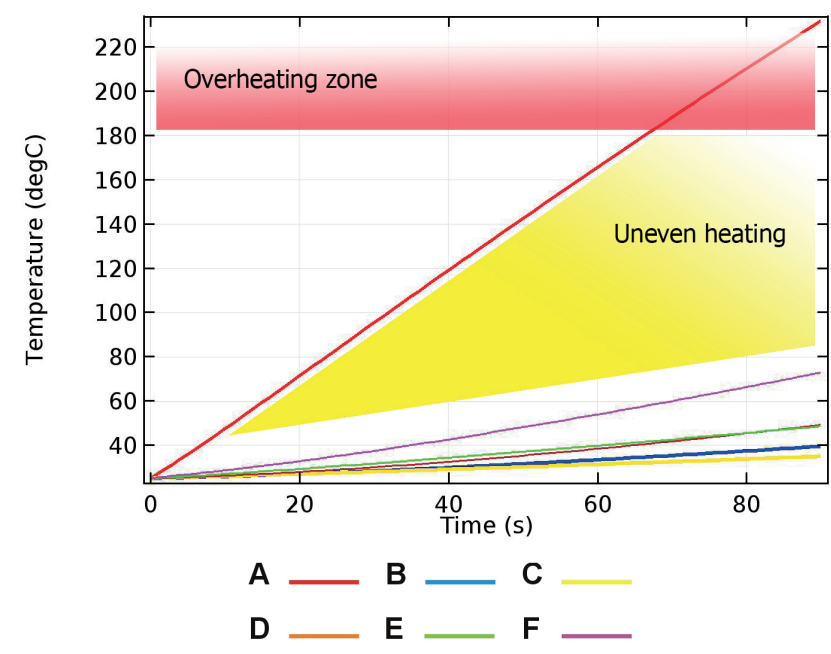

Fig. 8 The temperature rising in the points of measurement

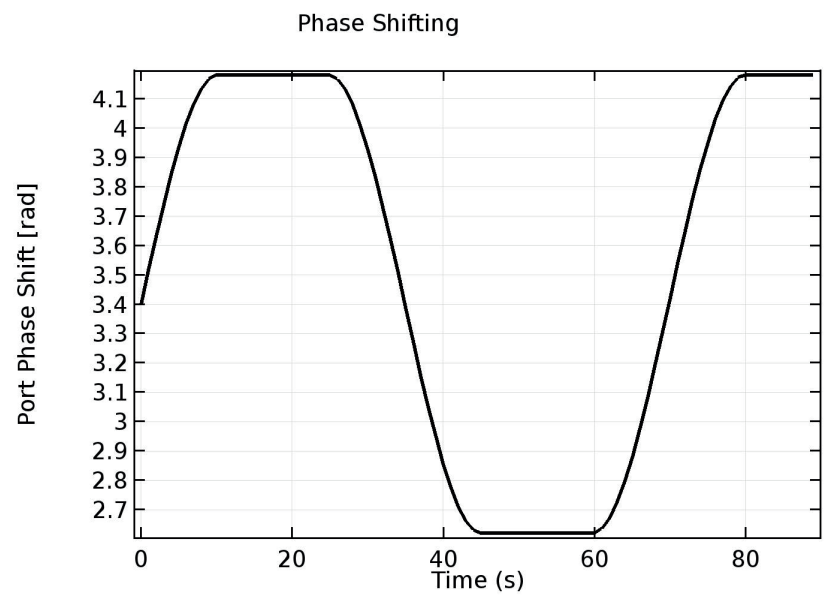

Fig. 9 Dynamics of the phase value $\boldsymbol{\theta}_{P 2}$ change

ports (measuring points B, D, F, E (Fig. 4)), there is a variable level of electromagnetic field tensity. In the central regions of the being heated material (measuring point $\mathrm{C}$ (Fig. 4)) the high tensity of the electromagnetic field is not observed (Fig. 11).

\subsection{The Change in the Temperature of Silica Gel under the Condition $\boldsymbol{\theta}_{P 1}=0 \mathrm{rad}$ and} $\theta_{P 2}=\boldsymbol{a b s}(w v 1(\boldsymbol{t})+1.1 \pi) \mathbf{r a d}$

In this paper, a dynamic picture of increasing the temperature in the adsorbent layer in case of phase rotates was obtained (Fig. 13 B).

In the central regions of the material being heated (measuring points $\mathrm{C}$ (Figs. 4, 12)) the heating intensity is low, but temperature increases with the similar intensity in the regions of the material being heated, located both in the
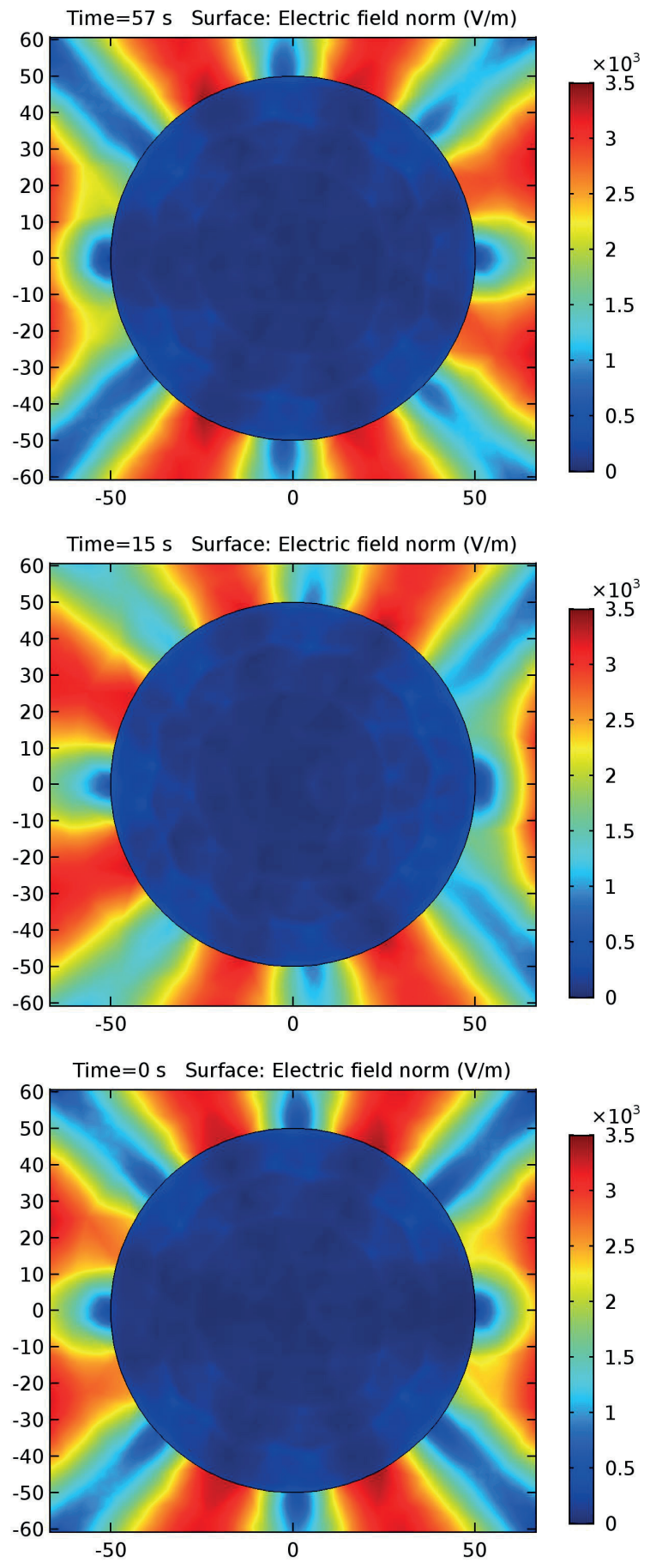

Fig. 10 The picture of the intensity of the electromagnetic field

immediate proximity of the ports (measuring points A (Fig. 4)), and in areas, that are remote from the ports (measuring points and B, D, F, E (Figs. 4, 12)).

Thus, due to the use of the phase rotation effect, a more uniform temperature increase is achieved in the bulk of the material (Fig. 14). Flow of heat has discrete uniform distribution in comparison with the action on the material by the phase stationary (Fig. $13 \mathrm{~A}$ ). 
Alternate Phase. E-field intensity graph.

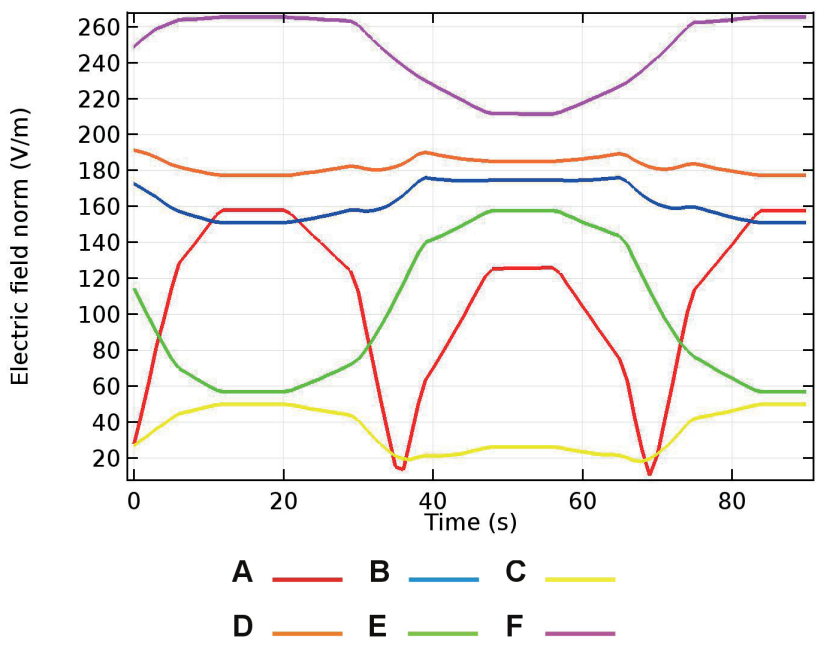

Fig. 11 The level of tensity of the electromagnetic field

Alternated Phase. Temperature graph.

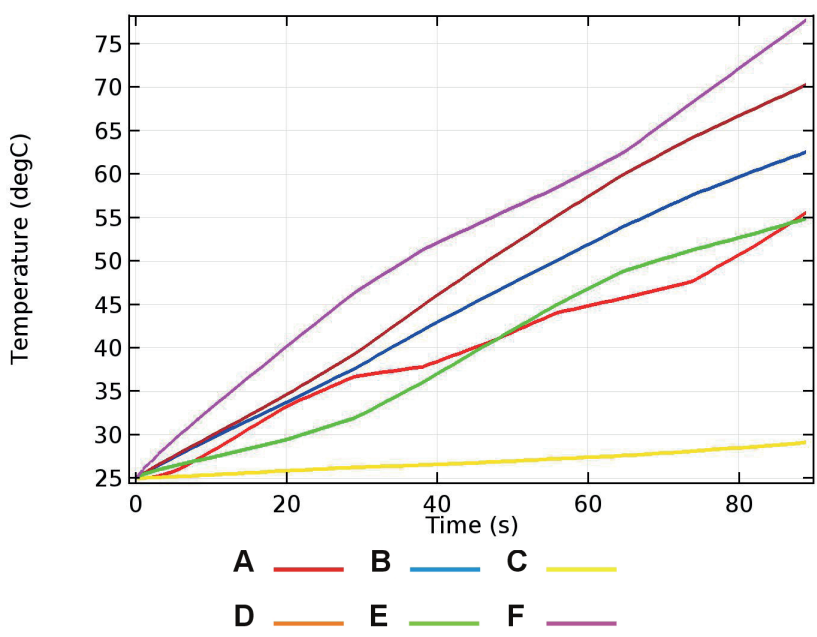

Fig. 12 The temperature rising in the points of measurements

\section{Conclusions}

In general, the conducted investigations show the possibility and advisability of phase rotation in order to increasing the uniformity of the effect of microwave energy on the volume of the adsorbent.

Preventing silica gel overheating during heating is an important task that can be solved through the rotation of the phases, not only by means of moving the material. This is especially important in conditions, where the movement of the material being heating is difficult from a technical point of view.

The scientific novelty of the work is the idea of using a heating chamber of a cylindrical shape and achieving uniform heating by changing the phase of one of the opposite ports, without shifting or rotating the silica gel.

The data obtained using a mathematical model was almost applicate for construction the test bench (Fig. 14). Practical experiments on the indicator adsorbent confirm the positive effect of phase rotation on the uniform distribution of temperature in the volume of the adsorbent. Also, in this case, there is a general decrease in the intensity of adsorbent heating which indicates a slight decline in the efficiency of microwave exposure during the phase rotation.

The obtained data contribute to the improvement of the design of the existing sample of industrial equipment and the creation of new adsorption dryer's constructions with microwave regeneration of the adsorbent. The results of this work can be used by machine-building enterprises producing compressed air preparation equipment. 


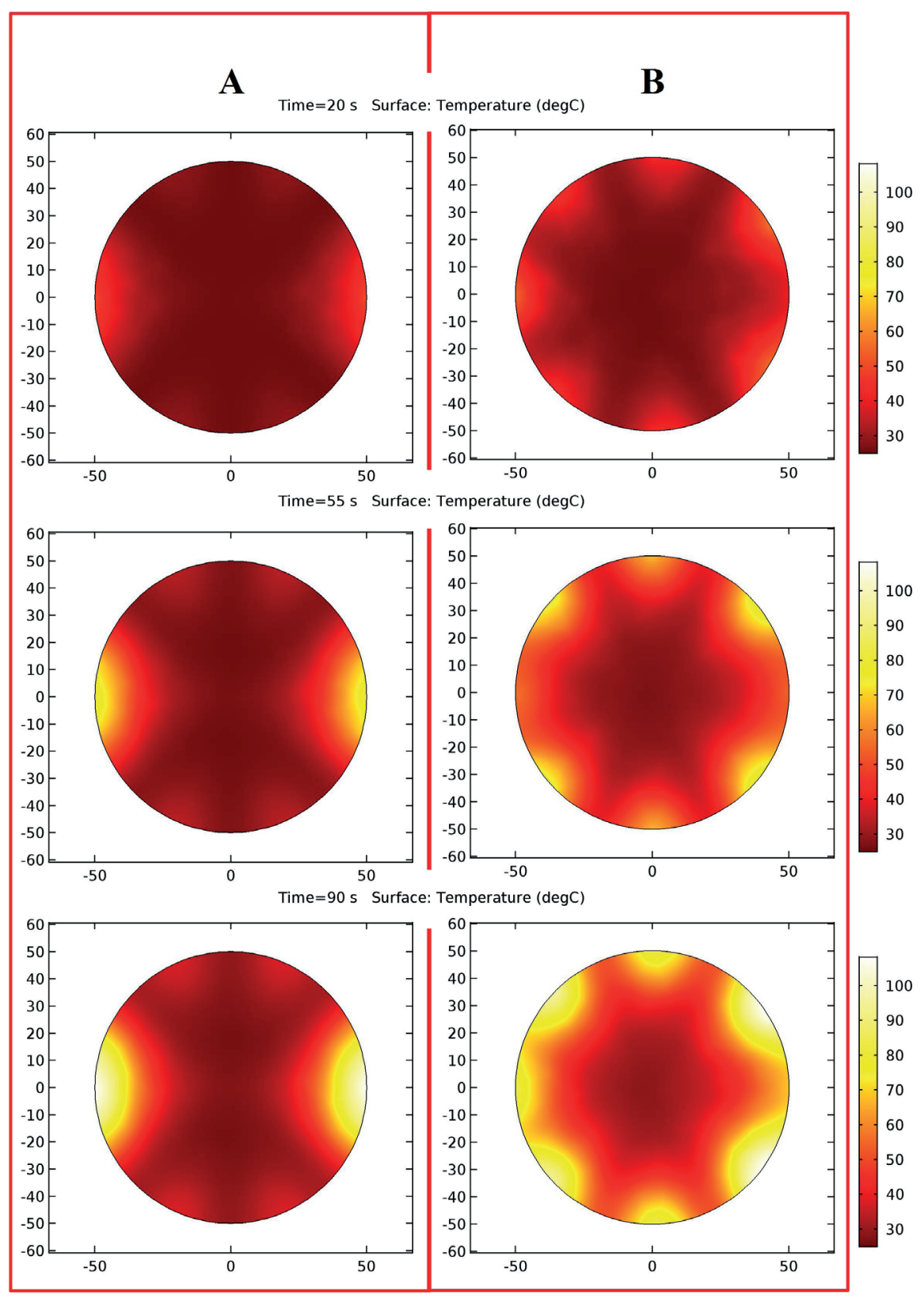

Fig. 13 Temperature is rising in the adsorbent layer. A - phase stationary, B - phase rotates.

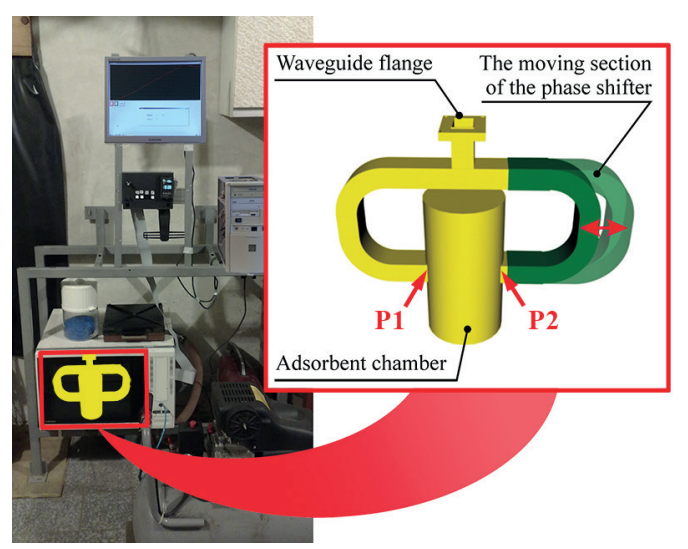

Fig. 14 The test bench with installed chamber and waveguide system 


\section{References}

[1] Dobrotvorskiy, S. S, Salenko, D., Aleksenko, B. "Obzor oborudovaniya i rashodnyih materialov, neobhodimyih dlya osusheniya szhatogo vozduha libo gazov" (Review of equipment and supplies required for dry air or gas), Bulletin of the National Technical University «Kharkiv Polytechnic Institute», Series: Technologies in mchanical engineering, 5(1177), pp. 71-74, 2016. [online] Available at: http://library.kpi.kharkov.ua/files/Vestniki/2016_5.pdf [Accessed: 10 February 2018] (in Russian)

[2] Jones, S. "Comparing Microwave to Conventional Heating and Drying Systems", [online] Available at: http://www. chemicalprocessing.com/assets/wp_downloads/pdf/comparing-microwave-to-covnetional-heating-drying-systems-v2.pdf [Accessed: 10 May 2018]

[3] Gao, F. "Comparison of Microwave Drying and Conventional Drying of Coal", Master Thesis, Queen's University, Kingston, Ontario, Canada, 2010. [online] Available at: http://hdl.handle. net/1974/6258 [Accessed: 15 May 2018]

[4] Tanaka, K., Asakuma, Y., Saptoro, A., Phan C. "Surface tension profiles of nanofluid containing surfactant during microwave irradiation", IOP Conference Series: Materials Science and Engineering, 206, article ID: 012011, 2017.

https://doi.org/10.1088/1757-899X/206/1/012011

[5] Dobrotvorskiy, S., Aleksenko, B., Dobrovolska, L., Basova, Y. "Effect of the Application of Microwave Energy on the Regeneration of the Adsorbent", Acta Polytechnica, 58(4), pp. 217-225, 2018. https://doi.org/10.14311/AP.2018.58.0217

[6] Parmar, H., Asada, M., Kanazawa, Y., Asakuma, Y., Phan, C. M, Pareek, V., Evans, G. M. "Influence of Microwaves on the Water Surface Tension", Langmuir, 30(33), pp. 9875-9879, 2014. https://doi.org/10.1021/la5019218

[7] Parmar, H., Asada, M., Kanazawa, Y., Asakuma, Y., Phan, C. M., Pareek, V., Evans G. M. "Reply to Comment on "Influence of Microwaves on the Water Surface Tension"'", Langmuir, 31(39), pp. 10933-10934, 2015.

https://doi.org/10.1021/acs.langmuir.5b02378

[8] Amiri, M. T., Amiri, M. C. "Comment on "Influence of Microwaves on the Water Surface Tension"', Langmuir, 31(39), pp. 10931-1093, 2015.

https://doi.org/10.1021/acs.langmuir.5b00780

[9] Fesenko, A., Yevsiukova, F., Basova, Y., Ivanova, M., Ivanov, V. "Prospects of Using Hydrodynamic Cavitation for Enhancement of Efficiency of Fluid Working Medium Preparation Technologies", Periodica Polytechnica Mechanical Engineering, 62(4), pp. 269-276, 2018. https://doi.org/10.3311/PPme.11877

[10] Lykov, A. V. "Teoriya sushki" (The Theory of Drying), 1st ed., Energyja, Moscow, Russia, 1968. (in Russian)

[11] Berteli1, M. N., Rodier, E., Marsaioli Jr., A. "Study of the Microwave Vacuum Drying Process for a Granulated Product", Brazilian Journal of Chemical Engineering, 26(02), pp. 317-329, 2009. https://doi.org/10.1590/S0104-66322009000200009
[12] Adamski, W., Kitlinski, M. "A Set-up to Determine Energy Absorption during Microwave Heating", In: $12^{\text {th }}$ International Conference on Microwaves and Radar, MIKON-98, Vol. 2, Krakow, Poland, 1998, pp. 633-637. https://doi.org/10.1109/MIKON.1998.740936

[13] Monolakov, V. A., Yudin, V. V., Ulyanovsk State Technical University "Sposob sushki pilomaterialov", (The method of drying lumber) Russia, Pat. 2113666 RF, 1998. (in Russian)

[14] Dobrotvorskiy, S., Dobrovolska, L., Aleksenko, B., Basova, Y. "The Use of Waveguides with Internal Dissectors in the Process of Regeneration of Industrial Adsorbents by Means of the Energy of Ultrahigh-Frequency Radiation", In: Ivanov, V., Rong, Y., Trojanowska, J., Venus, J., Liaposhchenko, O., Zajac, J., Pavlenko, I., Edl, M., Perakovic, D. (eds.) Advances in Design, Simulation and Manufacturing, Lecture Notes in Mechanical Engineering, 1st ed., Springer, Cham, Switzerland, 2019, pp. 433-442. https://doi.org/10.1007/978-3-319-93587-4_45

[15] Gareev, F. H. "Ustanovka dlya sushki dielektricheskih materialov svch-energiey" (Installation for drying the dielectric materials of microwave materials), Russia, Pat. 2199064 RF, 2003. (in Russian)

[16] Schulte, M., Omar, A. S. "Field Theoretical Analysis of Microwave Ovens", In: $21^{\text {st }}$ European Microwave Conference, Stuttgart, Germany, 1991, pp. 884-888. https://doi.org/10.1109/EUMA.1991.336414

[17] Möller, M., Linn, H. "Microwave Drying of Refractory Materials", Ceramic News Refractories, 5, Special Issue, pp. 79-80, 2001. [online] Available at: https:/www.linn-high-therm.de/fileadmin/user_upload/pages/about_us/download/publications/microwave_heating/Microwave_Drying_of_Refractory_Materials.pdf [Accessed: 10 June 2018]

[18] Polaert, I., Ledoux, A., Estel, L., Huyghe, R, Thomas, M. "Microwave assisted regeneration of zeolite", In: Cognet, P., Cabassud, M., Carine, J., Poux, M., Wilhelm, A.-M. (eds.) 1st International Congress on Green Process Engineering, Toulouse, France, 2007, Récents Progrès en Génie des Procédés, 94, Societe Francaise de Genie des Procedes (SFGP), Paris, France, pp. 1-8, 2007. [online] Available at: http://inpact.inp-toulouse.fr/GPE2007/ textes/text104.pdf [Accessed: 15 June 2018)]

[19] Hosseinzadeh, S., Yari, A., Radmanesh, M. "The Numerical Study of Channel Flow in Turbulent Free Convection with Radiation and Blowing", International Journal of Recent advances in Mechanical Engineering (IJMECH), 3(2), pp. 11-26, 2014. https://doi.org/10.14810/ijmech.2014.3202

[20] Hoseinzadeh, S., Azadi, R. "Simulation and optimization of a solar-assisted heating and cooling system for a house in Northern of Iran", Journal of Renewable and Sustainable Energy, 9(4), article ID: 045101, 2017. https://doi.org/10.1063/1.5000288

[21] Esmaeil Yousef Nezhad, M., Hoseinzadeh, S. "Mathematical modelling and simulation of a solar water heater for an aviculture unit using MATLAB / SIMULINK", Journal of Renewable and Sustainable Energy, 9(6), article ID: 063702, 2017. https://doi.org/10.1063/1.5010828 
[22] Hoseinzadeh, S., Ghasemiasl, R., Havaei, D., Chamkha, A .J. "Numerical investigation of rectangular thermal energy storage units with multiple phase change materials", Journal of Molecular Liquids, 271, pp. 655-660, 2018. https://doi.org/10.1016/j.molliq.2018.08.128

[23] Hoseinzadeh, S., Sahebi, S. A. R., Ghasemiasl, R., Majidian, A. R. "Experimental analysis to improving thermosyphon (TPCT) thermal efficiency using nanoparticles / based fluids (water)", The European Physical Journal Plus, 132(5), article ID: 197, 2017. https://doi.org/10.1140/epjp/i2017-11455-3

[24] Yari, A., Hosseinzadeh, S., Golneshan, A. A., Ghasemiasl, R., "Numerical Simulation for Thermal Design of a Gas Water Heater With Turbulent Combined Convection", In: ASME / JSME / KSME 2015 Joint Fluids Engineering Conference, Seoul, South Korea, 2015, pp. V001T03A007. https://doi.org/10.1115/AJKFluids2015-3305

[25] Orfanidis, S. J. "Electromagnetic Waves and Antennas", 1st ed., Rutgers University, New Jersey, USA, 2016. [online] Available at: http://eceweb1.rutgers.edu/ orfanidi/ewa/ [Accessed: 10 September 2018]
[26] ANSYS "ANSYS HFSS: 3D Electromagnetic Field Simulator for RF and Wireless Design", [online] Available at: https://www.ansys.com/ products/electronics/ansys-hfss [Accessed: 15 September 2018]

[27] ECE Illinois "22 Phasor form of Maxwell's equations and damped waves in conducting media", In: ECE-329 Fields and Waves I: Lecture Notes, ECE Illinois (University of Illinois, Department of Electrical and Computer Engineering), Electronic resource, 2016. [online] Available at: http:/jsa.ece.illinois.edu/ece329/ notes/329lect22.pdf [Accessed: 10 August 2018]

[28] Azo Materials "Silica - Silicon Dioxide $\left(\mathrm{SiO}_{2}\right)$ ", 2001. [online] Available at: http://www.azom.com/properties.aspx?ArticleID=1114 [Accessed: 18 June 2018]

[29] Ng, K. C., Chua, H. T., Chung, C. Y., Loke, C. H., Kashiwagi, T., Akisava, A., Saha, B. B. "Experimental investigation of the silica gel-water adsorption isotherm characteristics", Applied Thermal Engineering, 21(16), pp. 1631-1642, 2001.

https://doi.org/10.1016/S1359-4311(01)00039-4 